\title{
Interpretation of Homeland Feelings in Works of Bunin
}

\author{
Yanling Lu \\ Mudanjiang Normal University, Mudanjiang Heilongjiang, 157011, China
}

Keywords: Bunin's work, Homeland feeling, Natural animals and plants, Peasants.

\begin{abstract}
Bunin was an excellent inheritor of Russian literature. Most of his works reflect folk culture. Folk culture contained in his works shows his affirmation, inheritance and development of traditional culture of his motherland and meanwhile reflects national sentiments of Bunin. Bunin's novels mainly involve natural animals and plants, peasants and childhood etc. His works can show strong homeland feelings. This paper mainly discusses homeland feelings contained in his works through the analysis on Bunin's works.
\end{abstract}

\section{Introduction}

In the development process of Russian literature, writers in different eras had different understandings of folk culture of their own nations. However, they liked showing folk culture in their works. Bunin was the representative of Russian local writers. His creative process was filled with rich folk materials, explored Russian national character and soul and showed the development process of Russian and the memory of the whole era. This paper will analyze homeland feelings in Bunin's works from the perspective of natural animals and plants, peasants and childhood in Bunin's works.

\section{Show dynamic natural plants}

Russian nation gradually formed and developed in nature. Free nature with vast land makes the character of Russian nation more personalized. This makes Russian litterateurs pay more attention to feelings about nature. Therefore, factors of nature occur in their works more easily. Famous Russian writers Tolstoy and Turgenev et al. often described nature in their works. Plekhanov thought, "nature written by Tolstoy is not described with a pen; instead, it lives in men of literature and arts.” Though winning great praise of Plekhanov, Tolstoy thought that he still had great gap with Turgenev in the description of nature. Turgenev always advocated the harmony between human and nature. Inner feelings of human and nature were combined organically in his famous literature A Sportsman's Sketches ${ }^{[1]}$.

Bunin grew up in the field without human habitation. As he grew up in a manor away from city noise, Bunin had deeper feelings about nature. Bunin regarded nature as the source of his character description. Observations on nature were the source of his writing and philosophical thinking. Bunin was deeply influenced by the thought of literature writers such as Pushkin and Tolstoy. Especially in the description of nature, Bunin inherited the legacy of these literary masters. However, Bunin did not imitate them blindly in the process of inheriting natural local culture; instead, he recreated works on the shoulder of giants. Therefore, we can see his descriptions about light and color, breath and pulse of nature in his works. In the view of Bunin, natural plants did not lack emotion and nerve. He thought, "Though natural plants cannot act, they have dynamic and intelligence." Therefore, the flexibility of natural plants was depicted in many of his works. His writing included white birch with fresh and bitter flavor, singing birds and staggered birch forest. Tactile, auditory and visual descriptions about these sceneries can show a forest with vigor. Lie Nikulin highly appreciated Bunin. He thought that Bunin described nature, peasants and country life in middle Russia in a dynamic and lively rhythm with amazing skills. This is one of the reasons why Bunin's works became model in the academic world of Russia. 


\section{Show personalized natural animals}

Bunin had deep love and tender feelings for living creature in nature. This is manifested not only in his descriptions about plants, but also in his personalized descriptions about natural animals. In the writing of Bunin, animals such as swallow and hunting dog were not simple creature without mature thinking. Bunin endowed certain feelings to them. They had their own emotion and thought and can communicate with human beings. Therefore, human and animals were equal and harmonious in the thought of Bunin. Due to the existence of these personalized animals, the rural world written by Bunin became warmer and filled with vitality.

Animals written by Bunin were spiritual. In the process of describing animals, he used the method of describing people and then endowed stronger intelligence to animals. All readers marveled at such descriptions. For example, in the process of describing swallows, Bunin described them as beauty and their voice as happy twittering and used personalized words such as exquisite, cute, pure and gentle to describe the appearance, posture and character of swallows. In the process of describing a horse, Bunin described a horse chewing oat and hay with words "grinding oat into milk" and used word "gentle" to describe its lip. The eye expression of horse was described with words "august and cross-eyed". Therefore, these horses were no longer livestock carrying cargo for people in the writing of Bunin; instead, they were friends who can communicate with human beings. Even jackdaw was described as sister by him. In the view of Bunin, animals were emotional and they needed the respect of human beings and needed to get on with them as friends. This is a main reason for personalized descriptions of animals by Bunin. Moreover, Bunin also described movements of animals in detail, e.g. descriptions about hunting dog Charlma. Bunin described Charlma as lively and active naughty child. In particular, his descriptions about Charlma drinking water beside the pond and falling into water carelessly made Charlma filled with intelligence and showed his love for it.

Bunin not only had personalized descriptions about the appearance, movement and shape of animals, but also connected animals and his own situation in his writing. For example, in descriptions of his work The Life of Arseniev, Bunin connected his own situation with a pony. In his descriptions, the pony became a friend communicating with him and sharing pain and sadness. Therefore, Bunin seemed to describe the pony, but in essence wrote his own situation in the work. Bunin lived in the free and easy nature and had a light-hearted manor life from childhood. However, due to the demand for attending school, Bunin had to say goodbye to the light-hearted childhood and enter the limited middle school life. Bunin was painful and terrified. When he was governed by the teacher and had to obey the teacher and implement learning tasks, he thought of the pony being released to work without its permission. This was completely contrary to the free life with the pony imagined by him. They had to go against their will, leave their familiar environment and reliant mother and face the subsequent path with confusion, scare and fear ${ }^{[3]}$.

\section{Show care for peasants}

In the era when Bunin lived, intellectual stratum was a special social group. They shouldered the heavy responsibility of historical and social development. Russian intellectual stratum had stronger sense of social responsibility in national development. They had strong awareness of care for the fate of their nation. In the view of American scholar Lewis Kordsa, Russian intellectual stratum had strong social consciousness and could be in the state of preparing for political war at any time for the fate of the nation and state.

Such strong consciousness of Russian intellectual stratum provided Russian literature with more humanitarian spirit. It was mainly manifested into the care for the fate of peasants. In Russian literature, many famous litterateurs truly described the fate and miserable life of people at the lowest level of the society, including not only compassion but also praise for their power and wisdom, their courage in resisting against vicious power and their worry about the confused future. As typical Russian intellectual stratum, Bunin had all features of the stratum. Therefore, he inherited the Russian spirit of ancestors in his literary creation, spent a lot of energy on discussion on peasants' issues and fully manifested humanitarian spirit ${ }^{[4]}$.Famous master works include Ququ, Countryside, Ignat and 
Suchodol etc., which reflected peasants' issues from different perspectives. Though Bunin was born in a rich noble family, his family fortunes declined. Therefore, Bunin had to stop schooling and work in the city for making a living. He experienced sufferings of life at a young age. He lived among beggars and the old. In the down-and-out life, Bunin was one among them. Therefore, similar life experience allowed them to have deeper understandings of people at the low level and feel their inner suffering and struggle. Therefore, Bunin described the material poverty and spiritual emptiness of people at the low level in his writing with care for such people. Bunin could not help them with his own efforts. Therefore, he could only record their hardship and helplessness with a pen and paper.

There were many descriptions about poor peasants in his writing, e.g. Countryside, Alien Land and Withered Grass. Especially in Withered Grass, Bunin described an old long-term hired hand with serious disease, thus describing the poverty in rural Russia vividly. However, there were also descriptions about other long-term hired hand ignoring the old long-term hired hand in the work so as to show the common phenomenon of the old long-term hired hand. People saw such common occurrence and clearly aware that the current day of the old long-term hired hand would inevitably be the future of them. Therefore, indifference was the best way of avoidance. The old long-term hired hand was not afraid of death. He looked forward to the coming of God. Death became the only liberation for him. Faced with human sufferings, Bunin was so sad and could only pray that the old long-term hired hand could return to the God and free himself permanently. It was the only thing that Bunin could do for him.

In the process of describing the phenomenon of rural poverty, Bunin also reflected good characters of Russian peasants such as forbearing and goodness. His work Ququ depicted a father with noble emotion. Ququ and his adopted son got lost in the grassland without human habitation. However, facing the frozen adopted son without power, Ququ did not abandon him; instead, he put his adopted son on his stooping back and walked till daybreak. The great image of such a small potato Ququ and the inner tininess and lowliness of employer formed distinct contrast. Meanwhile, he depicted the brilliant image of Zahar Vorobyov in his work Zahar Vorobyov. Zahar Vorobyov had a strong body and kind heart. However, such good life did not escape the fate of passing away early. The work deeply reflected the darkness of Tsar governance and criticized the harm of Tsar governance to people.

\section{Show yearning for childhood}

Bunin completed his autobiographical novel The Life of Arsenyev after being about to enter his life of old age. When he was young, his life was out at the elbows and he experienced the hardship and suffering in life. After he became famous, his life was improved, but he left his native place and was homesick. Therefore, Bunin yearned for his light-hearted and free childhood most. The innocence, enjoyable grass land, playmates, teachers and parents were the best memory of an old man. Everything seemed to happen yesterday ${ }^{[5]}$.

Bunin grew up in the countryside. Therefore, his memory for the childhood was about rural life. Though the rural life was poor, it did not hinder his love for it. In the countryside, Bunin could smell the flavor of rice flower and green grass, see the ups and downs of rippling wheat and hear birdcall, the voice of guitar of his father and the singing of his mother. Bunin lived in the peaceful and free rural environment happily.

His playmates in the childhood were also unforgettable. Bunin described his playmates with great care and could show his playmates vividly to readers. For example, in his descriptions about a shepherd boy, he not only described his appearance and clothes in detail, but also carefully depicted his action of cracking a whip. Under the guidance of such a naïve shepherd boy accompanied by nature, Bunin contacted with natural native soil more closely. They could get into the vegetable plot to lick verdant stem, taste young cucumber filled with lump and eat turnip with soil. These descriptions showed the passion of children. Such passion was the best present given to Bunin by his native pland and was a wonderful memory yearned for by Bunin after he moved to France. 


\section{Conclusion}

Bunin was a typical representative of Russian local writers. His works depicted flexible natural plants, personalized natural animals, poor peasants and wonderful memory in the childhood. Russian worship to nature endowed literature writers with a sharp artistic temperament of yearning for freedom. Therefore, they paid more attention to descriptions about nature and endow nature with more intelligence and humanity in the creative process of literary works. Meanwhile, Bunin paid more attention to descriptions about peasants in his works. On the one hand, Bunin lived with them, had similar experiences and could understand their spiritual world; on the other hand, Bunin had typical spirit of Russian intellectuals and they paid more attention to people, especially laboring people at the low level. Therefore, Bunin showed the poor life and spirit of peasants in the countryside in his novels. Finally, for Bunin with certain fame in the literary world who moved overseas, the best memory was his childhood in the countryside. He could only maintain the deep love for the motherland through wonderful memory of his childhood.

\section{Acknowledgments}

This paper is general youth program of Mudanjiang Normal University in 2014, No. QY2014025.

\section{References}

[1] Wu Chuanyan. Discussions on Homeland Feelings in Bunin's Writing, Northern Literature: II, 2012(3):12-13.

[2] Zhao Shuang. Brief Discussions on Writing Style of Russian Writer Bunin, Northern Literature: II, 2012(1):24-25.

[3] Liang Xiaolin. Tragedy Consciousness of Bunin's Novel Countryside, Northern Literature: II, 2012(3):13-14.

[4] Yu Qiuying. Brief Analysis on Sadness in Bunin's Novel Countryside, Anhui Literature (Second Half), 2011(7):19-19.

[5] Yao Hua. Homeland Feelings in Bunin's Writing, Journal of Yancheng Institute of Technology (Social Science Edition), 2009,22(1):58-62. 